\title{
IDENTIFIKASI MORFOLOGI TUMBUHAN KANTONG SEMAR (NEPENTHES SP.) SEBAGAI BAHAN AJAR TUMBUHAN TINGKAT TINGGI DI KAWASAN WISATA GUNUNG GALUNGGUNG KABUPATEN TASIKMALAYA
}

\author{
Rinaldi Rizal Putra ${ }^{1,2)}$, Rita Fitriani ${ }^{1)}$ \\ ${ }^{1}$ Jurusan Pendidikan Biologi, FKIP, Universitas Siliwangi \\ ${ }^{2}$ Laboratorium Botani, Jurusan Pendidikan Biologi, FKIP, Universitas Siliwangi \\ Email korespondensi: rinaldi.rizalputra@unsil.ac.id \\ Diterima 15 Agustus 2018disetujui 31 Agustus 2018
}

\begin{abstract}
Mount Galunggung is one of the tourism icons in Tasikmalaya Regency which has highly potential of biodiversity, especially in various of plants. In addition to showing the natural tourism, Mount Galunggung is also a media for learning high-level plants for developing science in the university. One of the potential diversity of plants in Mount Galunggung is kantong semar, which is known with botanical name as Nepenthes sp. Nepenthes are known as tropical plants that can live and survive in extreme conditions with low nutrients. These plants are classified into carnivorous plants. This research was aimed to identify various species of Nepenthes in Tasikmalaya Regency based on morphological characters. This research was conducted in February until July 2018, located in Mount Galunggung Tasikmalaya Regency using descriptive and exploratory methods. Data collected were morphological identification of Nepenthes and environment conditions. Morphological identification was carried out by visual observation of organs in Nepenthes such as root, stem, leaf, pitcher, flower, fruit and seed that are expected to give preliminary data that can provide information to determine the classification. The result of this research concluded that only one species of Nepenthes was found in Mount Galunggung and that was included to Nepenthes gymnamphora.
\end{abstract}

Keywords: nepenthes; morphological identification; galunggung Mountain; teaching materials

\section{PENDAHULUAN}

Gunung Galunggung merupakan salah satu ikon wisata alam yang terdapat di Kabupaten Tasikmalaya, yang menyimpan kekayaan alam berupa flora dan fauna dengan ciri khas tersendiri. Berbagai flora dan fauna yang terdapat di Gunung Galunggung masih dapat bertahan hingga saat ini, walaupun kondisi ekologis dan vegetasinya sudah tidak lagi sealami beberapa periode ke belakang.

Berdasarkan hasil observasi awal, diketahui bahwa di kawasan Gunung Galunggung ditemukan beberapa jenis flora unik dan endemik yang belum pernah ditemukan di kawasan lainnya di Kabupaten Tasikmalaya, salah satunya yaitu tumbuhan kantong semar (Nepenthes sp.). Pada dasarnya, persebaran tumbuhan kantong semar (Nepenthes sp.) ini paling banyak ditemukan di Sumatera dengan jumlah 34 jenis dan 29 di antaranya adalah tergolong endemik. Sedangkan, di Jawa hanya dtemukan sebanyak 3 jenis dan 2 di antaranya tergolong endemik (Mansur,
2013). Mansur (2013) menyatakan bahwa keanekaragaman tumbuhan kantong semar di pulau Jawa masih tergolong rendah. Jenis kantong semar yang telah tercatat berada di Pulau Jawa yaitu Nepemthes gymnamphora, Nepemthes mirabilis, dan Nepemthes adrianii.

Keberadaan Nepenthes di habitat alaminya sudah mulai terancam akibat beberapa faktor, antara lain koversi menjadi lahan pertanian dan pertambangan, kerusakan habitat alami karena bencana atau perbuatan manusia, maupun eksploitasi yang berlebihan (Puspitaningtyas dan Wawangningrum, 2007; Handayani dan Dodo, 2005). Berdasarkan fakta tersebut, tumbuhan kantong semar digolongkan ke dalam tumbuhan langka.Menurut International Union for the Conservation of Nature(IUCN) tahun 2009 dan World Conservation Monitoring Centre(WCMC) tahun 2000. Di Indonesia, tumbuhan ini dilindungi oleh Undang-Undang No.5 tahun 1990 tentang Konservasi Sumber Daya Alam 
Hayati dan Ekosistemnya, serta Peraturan Pemerintah No.7 tahun 1999 tentang Pengawetan Tumbuhan dan Satwa.

Berbagai penelitian mengenai Nepenthes hingga saat ini yang tercatat berfokus pada penemuan spesies baru, seperti yang dilakukan oleh Cheek et. al. (2018) mengenai Nepenthes spesies baru di Raja Ampat. Selain pada penemuan spesies baru, penelitian mengenai Nepenthes pun berfokus pada status keterancamannya di suatu daerah, seperti yang dipublikasikan oleh Cheek (2015) mengenai status keterancaman Nepenthes di Halmahera. Selain itu, kajian etnobotani, fitokimia, dan farmakologi telah dilakukan pada Nepenthes, seperti yang dipublikasikan oleh Sanusi et. al. (2017).

Oleh karena beragamnya fokus penelitian pada Nepenthes, penelitian ini pun memiliki fokus pada identifikasi Nepenthessecara morfologis yang ditemukan di Kawasan Gunung Galunggung Kabupaten Tasikmalaya. Dengan adanya data morfologi Nepenthes yang ditemukan di kawasan Gunung Galunggung Kabupaten Tasikmalaya, diharapkan dapat memberikan kontribusi dalam pengembangan penelitian berikutnya, khususnya yang berkaitan dengan penemuan spesies baru, status konservasi, dan pengembangannya untuk bahan ajar Tumbuhan Tingkat Tinggi.

\section{METODE}

Penelitian ini dilaksanakan pada bulan Februari s.d. Juli 2018 di kawasan Gunung Galunggung Kabupaten Tasikmalaya. Fokus penelitian ini adalah identifikasi morfologis tumbuhan kantong semar (Nepenthes) di kawasan Gunung Galunggung Kabupaten Tasikmalaya.

Penelitian ini menggunakan metode deskriptif eksploratif dengan teknik survey. Setiap jenis tumbuhan kantong semar (Nepenthes) yang ditemukan, diidentifikasi secara morfologis dari mulai bentuk dan ukuran daun, keberadaan bunga, dan bentuk serta ukuran kantong.

Alat yang digunakan dalam penelitian ini antara lain alat tulis, GPS, kompas manual dan digital, termometer, hygrometer, $\mathrm{pH}$ meter tanah, kamera digital, penggaris, buku panduan lapangan, dan tali rapia. Sedangkan, bahan yang digunakan dalam penelitian ini yaitu tumbuhan kantong semar (Nepenthes) yang ditemukan di kawasan Gunung Galunggung Kabupaten Tasikmalaya.

Observasi dilakukan dengan melakukan eksplorasi langsung ke kawasan Gunung Galunggung, khususnya kawasan bibir kawah bekas erupsi hingga ke ngarai. Observasi dilakukan dengan mengamati setiap lokasi yang diduga menjadi tempat hidup/habitat tumbuhan kantong semar (Nepenthes). Dokumentasi tumbuhan kantong semar (Nepenthes) dilakukan dengan teknik pengambilan gambar/foto dan pengoleksian dengan metode pengawetan contoh kantong.

Buku panduan lapangan yang digunakan bersumber dari van Steenis yang diterbitkan oleh Pusat Penelitian Biologi, Lembaga Ilmu Pengetahuan Indonesia (LIPI) Bogor (2006). Penentuan spesimen dilakukan dengan mencocokan spesimen dengan keterangan dan gambar yang terdapat pada buku panduan.

Langkah-langkah yang ditempuh dalam pelaksanaan dan pengambilan data dalam penelitian ini adalah sebagai berikut:

1. menyiapkan semua peralatan yang akan digunakan;

2. melakukan pengecekan terhadap semua peralatan yang akan digunakan;

3. melakukan observasi ke lokasi yang diduga menjadi tempat hidup tumbuhan kantong semar (Nepenthes);

4. menandai lokasi ditemukannya tumbuhan kantong semar (Nepenthes);

5. melakukan identifikasi secara morfologis dan mencocokan data dengan buku panduan lapangan; dan

6. melakukan pengambilan gambar yang selanjutnya akan dilakukan pengoleksian contoh kantong dengan menggunakan larutan pengawet.

\section{HASIL DAN PEMBAHASAN}

Berdasarkan hasil observasi dan identifikasi di lapangan, tumbuhan kantong semar (Nepenthes) yang ditemukan di 
Identifikasi Morfologi Tumbuhan Kantong Semar (Nepenthes sp.) sebagai Bahan Ajar Tumbuhan Tingkat Tinggi di Kawasan Wisata Gunung Galunggung Kabupaten Tasikmalaya

kawasan Gunung Galunggung berada pada ketinggian 1.180 mdpl dengan lokasi yang paling banyak ditemukan adalah di sekitar bibir kawah (Gambar 1). Kondisi habitat tempat ditemukannya Nepenthes ditampilkan pada Tabel 1.

Tumbuhan kantong semar (Nepenthes) yang ditemukan di kawasan Gunung Galunggung dideskripsikan sebagai berikut:

1. Akar: sistem perakaran tunggang;

2. Batang: berkayu dan tak bercabang, seringkali membentuk roset akar. Batang memiliki warna hijau kemerahan dengan arah tumbuh batang serong ke atas. Percabangan batang termasuk ke dalam simpodial. Bentuk batang bulat dengan tepi batang rata (laevis). Panjang batang rata-rata berkisar 25 s.d. $36,5 \mathrm{~cm}$;

3. Daun: Daun tunggal, berwarna hijau kemerahan, bangun daun lanset, termasuk ke dalam daun tak lengkap. Daun duduk memeluk batang, duduk daun tersebar, lebar daun bervariasi mulai dari 3,7 hingga 5,0 cm sedangkan untuk panjang daun bervariasi antara 16 hingga $32,5 \mathrm{~cm}$. Permukaan daun licin dan mengkilap, daun tebal dan berdaging. Perincian bangun daun sebagai berikut: pangkal daun truncatus, tepi daun rata (jnteger), ujung daun runcing (acutus), pola pertulangan daun melengkung. Terdapat rambut-rambut halus pada daun permukaan bawah (abaksial) dan permukaan batang; dan

4. Kantong: pada kantong muda berwarna hijau dengan sedikit bercak-bercak merah, sedangkan pada kantong yang sudah tua sebagian besar ditutupi oleh bercak merah. Panjang tangkai kantong bervariasi mulai dari 8,7 hingga $16,5 \mathrm{~cm}$, sedangkan panjang kantong sendiri bervariasi mulai dari 8,0 hingga $41,5 \mathrm{~cm}$. Bentuk kantong Nepenthes yang ditemukan di Gunung Galunggung ada dua jenis, yaitu Nepenthes dengan bentuk kantong upper (tangkai kantong berada di belakang) dan lower (tangkai kantong berada di depan atau samping). Bibir pada kantong membulat lebar, dengan penutup bibir berbentuk oval. Pada kantong terdapat sayap berambut dengan warna kemerahan.

Tabel 1. Kondisi habitat tempat ditemukannya Nepenthes di kawasan Gunung Galunggung

\begin{tabular}{|c|c|c|c|}
\hline Ketinggian (mdpl) & Kelembaban (\%) & Suhu $\left({ }^{\circ} \mathrm{C}\right)$ & Deskripsi Habitat \\
\hline $1.180-1.200$ & $83-87$ & $18-27,8$ & $\begin{array}{l}\text { Hamparan pasir yang sebagiannya } \\
\text { terututpi oleh tumbuhan lumut. Kondisi } \\
\text { tanah agak miring, sebagian besar } \\
\text { tertutupi oleh hamparan lumut, tumbuhan } \\
\text { yang hidup didominasi oleh tumbuhan } \\
\text { lumut, paku Gleichenia herba, semak, } \\
\text { perdu, dan sebagian kecilnya berupa } \\
\text { pohon yang tingginya mencapai } 3 \text { meter. }\end{array}$ \\
\hline
\end{tabular}



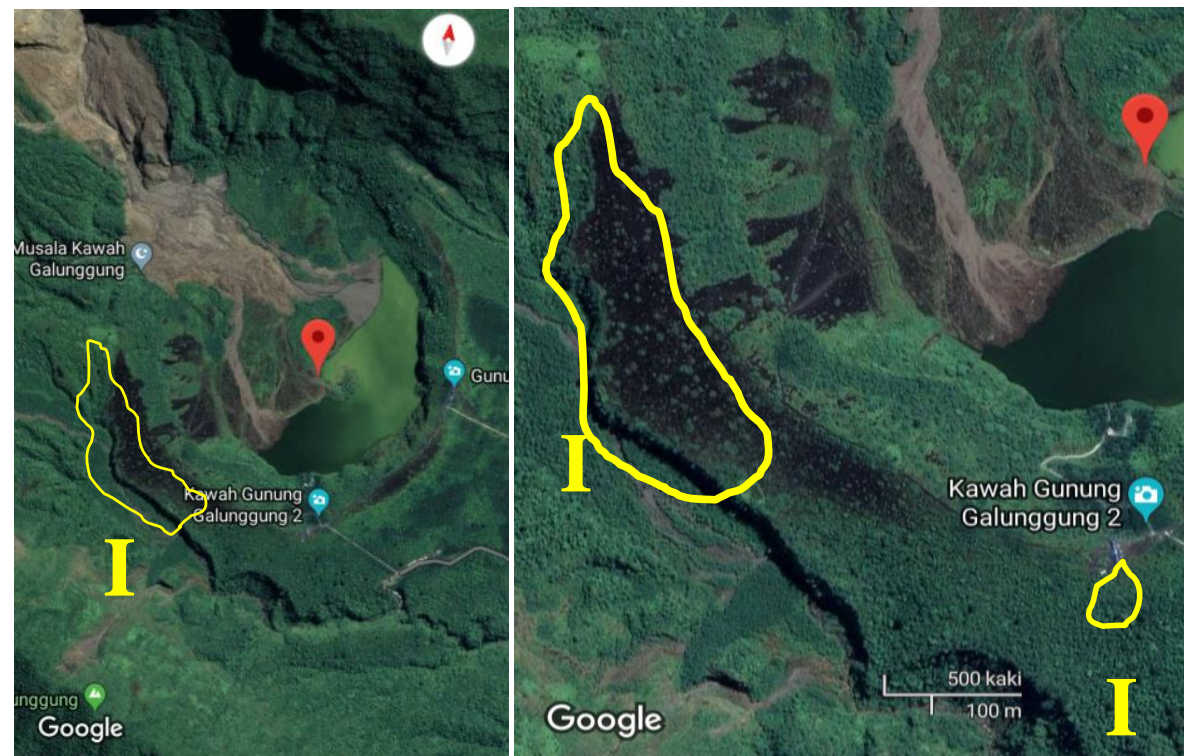

Gambar 1. Lokasi ditemukannya tumbuhan kantong semar (Nepenthes): I. Area pengami tan I; II. Area pengamatan II. (Sumber: Google Maps)
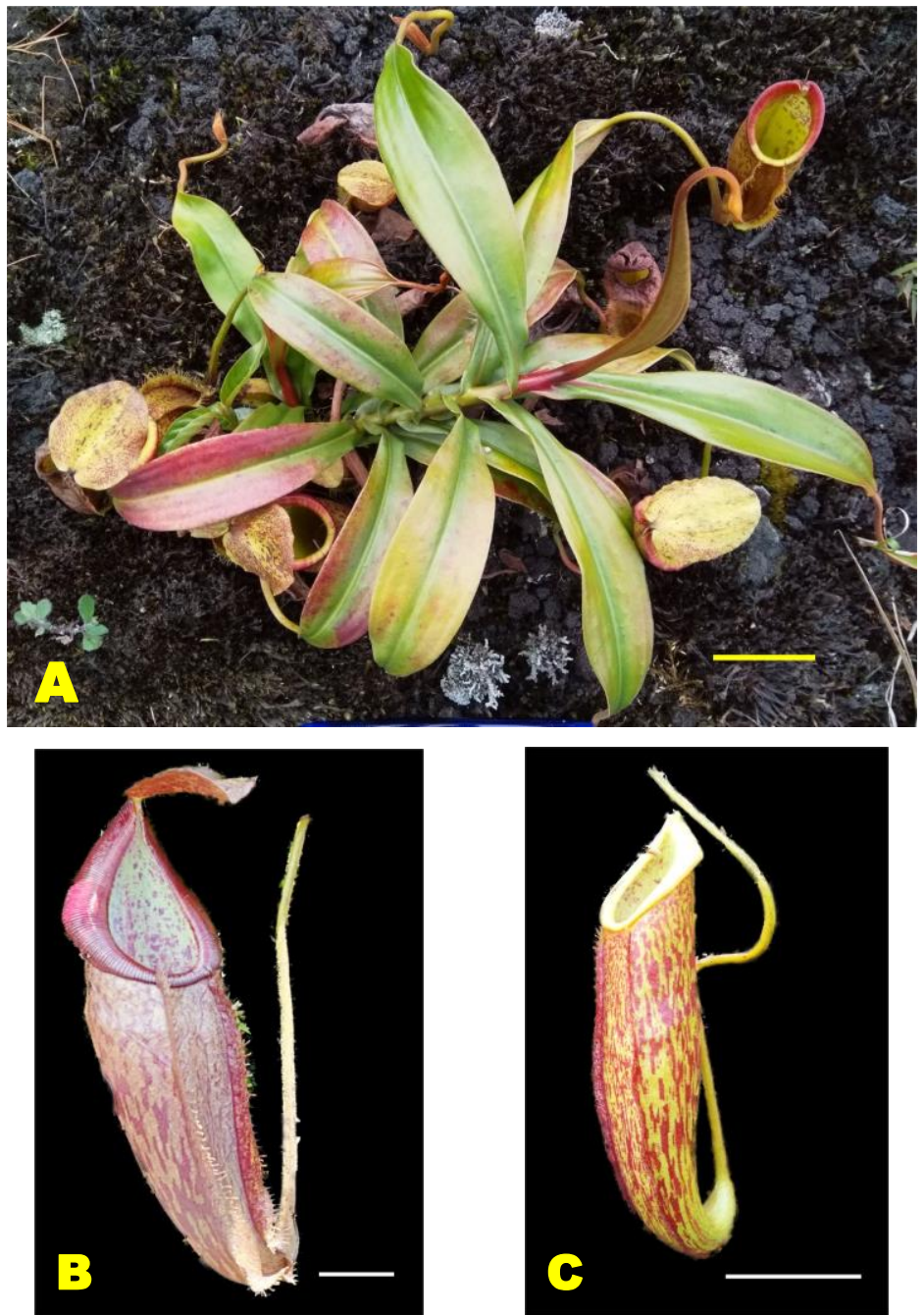

Gambar 2. Tanaman kantong semar (Nepenthes sp.) yang ditemukan di Gunung Galunggung Kabupaten Tasikmalaya. Tanaman keseluruhan $(\mathrm{A})(\mathrm{bar}=5 \mathrm{~cm})$; kantong dengan bentuk lower $(\mathrm{B})(\mathrm{bar}=2,5 \mathrm{~cm})$; dan kantong dengan bentuk upper $(\mathrm{C})(\mathrm{bar}=2,5 \mathrm{~cm})$. 
Identifikasi Morfologi Tumbuhan Kantong Semar (Nepenthes sp.) sebagai Bahan Ajar Tumbuhan Tingkat Tinggi di Kawasan Wisata Gunung Galunggung Kabupaten Tasikmalaya

Identifikasi suatu spesies tumbuhan Nepenthes dilakukan berdasarkan bentuk kantong yang telah terbentuk, warna kantong, bentuk dan warna bibir, ketebalan, dan habitat tempat ditemukan. Namun, hal yang pertama dijadikan sebagai patokan penentuan spesies didasarkan pada habitat tempat ditemukan.

Berdasarkan penelitian Batoro and Wartono (2017), menyebutkan bahwa Nepenthes yang ditemukan di Jawa terdapat tiga jenis, antara lain $N$. mirabilis, $N$. gymnamphora, dan $N$. adrianii. Hasil identifikasi ketinggian lokasi tempat ditemukan Nepenthes di Gunung Galunggung Kabupaten Tasikmalaya, habitat ditemukan Nepenthes berada pada ketinggian 1.180 - 1.200 mdpl. Kisaran ketinggian tersebut hanya memungkinkan ditemukan dua jenis Nepenthes saja, yaitu $N$. adrianii dan N. gymnamphora. Hal tersebut sesuai dengan pernyataan Batoro and Wartono (2017) dan Mansur (2012; 2013), yang menyebutkan bahwa Nepenthes yang ditemukan di Jawa berjumlah tiga jenis, dan dua di antaranya ( $N$. adrianii dan $N$. gymnamphora) ditemukan dihabitat dataran tinggi, berkisar 900 s.d. $2.750 \mathrm{mdpl}$.

Namun, untuk jenis $N$. adrianii merupakan endemik Gunung Slamet (Batoro and Wartono, 2017), dan belum pernah ditemukan di lokasi lainnya selain di sekitar Gunung Slamet. Dengan demikian, penulis berkesimpulan bahwa jenis Nepenthes yang ditemukan di Gunung Galunggung Kabupaten Tasikmalaya berdasarkan data morfologis dan kondisi habitat yang terdapat di Tabel 1 termasuk ke dalam jenis Nepenthes gymnamphora. Hal tersebut didukung oleh Batoro and Wartono (2017), yang menjelaskan bahwa $N$. gymnamphora memiliki karakteristik khusus antara lain kantong berwarna hijau dengan dominasi bercak merah atau sebagian besar merah ketika telah dewasa, terdapat sayap berambut dengan warna kemerahan, mulut/bibir membulat lebar, tutup kantong berbentuk oval, dan biasanya ditemukan di hutan pegunungan dengan ketinggian antara 1000 s.d 2750 mdpl.
Tumbuhan Nepenthes gymnamphora yang ditemukan di Gunung Galunggung khususnya, dan umumnya Nepenthes yang ditemukan di habitat lainnya, secara ekologis memiliki peran yang unik dan penting. Hal tersebut dikarenakan tumbuhan Nepenthes ini merupakan indikator iklim yang selalu basah (van Steenis, 2006). Oleh karena itu, tumbuhan ini seringkali hanya ditemukan di lokasi-lokasi yang selalu basah. Kemudian, tumbuhan Nepenthes seringkali ditemukan pada kondisi habitat yang ekstrem, dengan tanah yang sangat miskin unsur hara (Bauer et. al., 2015). Dengan demikian, terbentuknya kantong pada tumbuhan Nepenthes sebagai alat tambahan/modifikasi dari daun untuk memaksimalkan perolehan unsur hara/nutrisi dengan cara mengekstraksi tubuh hewan-hewan kecil sebagai sumber nutrisi tambahan. Oleh karena itu, untuk menarik hewan-hewan kecil seperti serangga agar masuk ke dalam kantong, terdapat semacam nektar sebagai penarik hewanhewan tersebut untuk masuk ke dalam kantong, yang didalamnya terdapat enzim yang mampu memecah dan mengekstraksi tubuh hewan tersebut.

\section{KESIMPULAN}

Tumbuhan Nepenthes yang ditemukan di Gunung Galunggung Kabupaten Tasikmalaya hanya ditemukan satu jenis saja, yaitu Nepenthes gymnamphora pada ketinggian $1.180-1.200$.

\section{SARAN}

Perlu penelitian lebih lanjut untuk mengetahui kekerabatan Nepenthes gymnamphora yang ditemukan di Gunung Galunggung Kabupaten Tasikmalaya dengan Nepenthes lainnya yang terdapat di wilayah Jawa lainnya. Selain itu, hasil penelitian ini dapat diadopsi sebagai suplemen pengembangan bahan ajar untuk mata kuliah Tumbuhan Tingkat Tinggi pada kurikulum Jurusan Biologi/Pendidikan Biologi di berbagai universitas, khususnya di Jurusan Pendidikan Biologi FKIP Universitas Siliwangi. 


\section{DAFTAR PUSTAKA}

Batoro, J. and Wartono, A. Review status the Nepenthes (Nepenthaceae) from Java Indonesia. Indian Journal of Plant Science, Vol. 6(1), pp. 12 - 16.

Bauer, U., Rembold, K., and Grafe, T.U. 2015. Carnovorous Nepenthes pitcher plants are a rich food source for a diverse vertebrate community. Journal of Natural History.

Cheek, M. 2015. Nepenthes (Nepenthaceae) of Halmahera, Indonesia. Blumea, 59, pp. $215-225$.

--------., Jebb, M., Murphy, B., and Mambor, F. 2018. Nepenthes section insignes in Indonesia, with two new species. Blumea, 62, pp. $174-176$.

Handayani, T., Latifah, D.and Dodo. 2005. Diversity and Growth Behaviour of Nepenthes (Pitcher Plants) in Tanjung Puting National Park, Central Kalimantan Province. Biodiversitas, vol. 6(4), pp. 248 - 252, Oktober 2005.

Mansur, M. 2012. Laju penyerapan $\mathrm{CO} 2$ pada kantong semar (Nepenthes gymnamphora Nees) di Taman Nasional Gunung Halimun - Salak, Jawa Barat. J. Tek. Ling., Vol. 13(1), pp. $59-65$.

---------. 2013. Tinjauan tentang Nepenthes (Nepenthaceae) di Indonesia.

Puspitaningtyas, D. M. dan Wawangningrum, H. 2007. Keanekaragaman Nepenthes di Suaka Alam Sulasih Talang-Sumatera Barat. Biodiversitas, vol. 8(2), pp. 152 - 156, April 2007.

Sanusi, S.B., Bakar, M.F.A., Mohamed, M., Sabran, S.F., and Mainasara, M.M. 2017. Ethnobotanical, Phytochemical, and Pharmacological Properties of Nepenthes Species: A Review. Asian Journal of Pharmaceutical and Clinical Research, Vol. 10(11), pp. 16 $-19$.

van Steenis, C.G.G.J. 2006. Flora Pegunungan Jawa. Bogor: Pusat Penelitian Biologi LIPI. 